Acta bot. bras. 1(2):195-207 (1988) supl.

\title{
DUAS ESPÉCIES NOVAS DE VELLOZIACEAE DE MINAS GERAIS
}

\author{
Renato de Mello-Silva (1) \\ Nanuza Luiza de Menezes (1)
}

\begin{abstract}
RESUMO - Duas novas espécies brasileiras de Velloziaceae são descritas: Pleurostima riparia N. Menezes \& Mello-Silva, conhecida somente de Gräo-Mogol e Vellozia luteola Mello-Silva \& N. Menezes, de Grão-Mogol e Itacambira, ambas do campo rupestre da Cadeia do Espinhaço, ao norte de Minas Gerais. São apresentadas descriçōes incluindo características morfológicas das partes vegetativas e florais e características anatômicas das folhas, além de ilustraçōes do hábito, flores e frutos. Também são discutidos os atributos característicos de cada espécie, assim como suas relaçōes com táxons afins.
\end{abstract}

\begin{abstract}
Two new brazilian species of Velloziaceae are described in this paper: Pleurostima niparia N. Menezes \& Mello-Silva and Vellozia luteola Mello-Silva \& N. Menezes, both from the Grāo-Mogol area, in the Espinhaço Range of Mountains, north of Minas Gerais. Descriptions including anatomical features of leaves and illustrations are presented. Also, the peculiar characters and taxonomic relationships of each species are discussed.
\end{abstract}

\section{Introdução}

Após a revisāo das Velloziaceae americanas publicadas por Smith \& Ayensu (1976), outras espécies da familia, que crescem no Brasil, têm sido descritas (Smith \& Ayensu 1979, 1980; Menezes 1980a; Smith 1985a, 1985b, 1986), além de ter sido restabelecido o gênero Pleurostima Raf. por Menezes (1980b). A maioria destas espécies são oriundas de formaçōes rupestres do Brasil, região onde a fam:lia atingiu sua máxima diversidade.

A famnia Velloziaceae, segundo Menezes $(1971,1973,1975,1984)$ está dividida em duas subfamilias: Barbacenioideae cujas espécies possuem flores com corona e os feixes vasculares das folhas envolvidas por uma bainha dupla (a interna endodérmica e a externa parenquimática) e Vellozioideae cujas espécies possuem flores sem corona e os feixes vasculares das folhas envolvidas por bainha simples (a endodérmica). Estudos recentes baseados na química de alcanos da cera foliar epicuticular de espécies da familia Velloziaceae (Salatino 1986) reforçam a separação das duas subfamilias como proposta por Menezes (l.c.).

Neste trabalho, duas novas espécies são apresentadas, ambas da Cadeia do Espinhaço ao norte de Minas Gerais, uma incluida na subfamilia Barbacenioideae (Pleurostira riparia N. Menezes \& Mello-Silva) e outra na subfamilia Vellozioideae (Vellozia luteola Mello-Silva \& N. Menezes).

(1) Depto. de Botânica, Instituto de Biociências, Universidade de São Paulo - C.P. 11.461 - 05499. São Paulo, SP. 
Pleurostima riparia N. Menezes \& Mello-Silva sp. nov. Figs. 1-10; 13-14.

Pleurostima delicatula (L.B. Smith \& Ayensu) N. Menezes proxime est affinis, discriminibus systematicis in diagnosi indicatus sufficienter recedit.

Planta caespitosa. Radices isabellinae. Caudex indivisus vel rarius bifurcatus, usque 7 cm longus, $1-2 \mathrm{~cm}$ latus, apicem versus folliis emarcides plus minusve laceratis reflexis tectus, basem versus foliorum vaginis 6-15 mm longis, 4.0-4.5 mm latis arcte adpressis, plus minusve laceratis, haud resinosis, glabris, albis, siccitatibus flavidis vel castaneis, tectus. Folia trifaria, superposita ad $2 \mathrm{~mm}$ distantia, chartacea vel subcoriacea, juniora erecta, mox erecto-patentia, tandem patentia, postrema, reflexa patentia lacerata, viventia ad $5-11$; limbo $3-11 \mathrm{~cm}$ longo, ad basem 2-6 mm lato, anguste triangulari, paulo arcuato, carinato, concolore, viridi, haud resinoso, marginato, 19-37 nervis ad medium, utrinque prominentibus, nervo medio supra impresso, subtus prominenti apicem versus strigoso, marginibus incrassatis apicem versus strigosis, cetero glabro. Bracteae nullae vel indistinctae. Flores longe pedunculati, pedunculis 1 raro 2, foliorum medio aequantis, 2.0-5.5 cm longis, circ. $1 \mathrm{~mm}$ latis, albi-viridibus, cylindricis, glabris; hypantho campanulato trigono, 12 usque 16-costato, albo-viride interdum leviter violaceo, glabro, 6-7 mm longo, fauce 3-5 mm ampla, circ. 3/4 partibus ovario adnatis; tepalis erecto-patulis, glabris, 3 exterioribus oblongis, cuspidatis, cuspide subtus strigosa, albis vel albi-violaceis, 6-13 mm longis, 2-4 mm latis, 3 interioribus paulo brevioribus et latioribus, $5-11 \mathrm{~mm}$ longis, $2-5 \mathrm{~mm}$ latis, 3 interioribis paulo brevioribus et latioribus, $5-11 \mathrm{~mm}$ longis, 2-5 mm latis, oblongis, acuminatis, albis; lobis coronae albis, oblongis, circ. $6 \mathrm{~mm}$ longis, 3 tepalis exterioribus oppositis circ. $2.3 \mathrm{~mm}$ latis, 3 tepalis interioribus oppositis angustioribus, circ. 1,5 mm latis, bilobulatis, lobulis triangularibus circ. $1 \mathrm{~mm}$ longis stylo subaequantibus vel aequantibus; antheris violaceis, basibus auriculatis, apicibus appendiculatus, basifixis, introrsis, circ. $4 \mathrm{~mm}$ longis, 2/3 longitudine loborum coronae, polline aureo; stylo trigono, albo, circ. $7 \mathrm{~mm}$ longo, ad base partis apicalis 3 stigmatibus lateralibus ovalibus. Capsula ovoidea truncata, castaneo-viridis, tandem castanea, costata, glabra, demum inter costas soluta hoc modo dehiscens, circ. $10 \mathrm{~mm}$ longa, circ. $6 \mathrm{~mm}$ diam.; semina numerosa, conico-pyramidata, circ. $1 \mathrm{~mm}$ longa, testa castanea vel brunnea, reticulata.

Habitat ad ripas fluminis Itacambiruçu prope Grão-Mogol (Minas Gerais).

Nomen oriundum ex loco ubi habitat.

Planta cespitosa. Raízes cor-de-areia. Cáudice simples ou mais raramente bifurcado, até 7 × 1-2 cm, recoberto, no ápice, pelas folhas reflexas; para a base, somente pelas bainhas foliares que são mais ou menos laceradas, não resinosas, glabras, alvas, in sicco amareladas a castanhas. Folhas trísticas, as vivas $5-11$, cartáceas a subcoriáceas, na mesma fileira distantes uma das outras até $2 \mathrm{~mm}$; limbo $3-11 \mathrm{~cm} \times 2-6 \mathrm{~mm}$ na base, estreitamente triangular, carenado, na região mediana 19-37 nervuras proeminentes em ambas as faces, nervura média impressa na face adaxial, na abaxial proeminente e estrigosa para o ápicc, margens espessadas do meio para o ápice estrigosas, restante do limbo glabro. Brácteas inexistentes ou indistintas. Pedúnculo floral 1, raro 2, 2,0-5,5 cm x $1 \mathrm{~mm}$,

Figs. 1-10 - Pleurostima riparia N.Menezes \& Mello-Silva (1-8 Mello-Silva et al. CFCR 8400; 9 - Martinelli 5821; 10 - Menezes et al. 1110.) Fig. 1 - Hábito com detalhe da face abaxial da folha. Fig. 2 - Ápice foliar, face abaxial, com tricomas estrigosos. Fig. 3 - Corte longitudinal da flor mostrando androceu e gineceu. Fig. 4 - Ápice da tépala externa com tricomas no cúspide. Fig. 5 - Tépala externa com lobo da corona e antera. Fig. 6 - tépala interna, idem. Fig. 7 - Lobo da corona cortado longitudinalmente mostrando inserção basifixa e apêndice apical da antera. Fig. 8 - Estilete com 3 estigmas laterais. Fig. 9 - Fruto imaturo, com costelas salientes. Fig. 10 - Fruto maduro, com desintegraçăo do tecido entre as costelas.

Figs. 11-12 - Pleurostima delicatula (L.B. Smith \& Ayensu) N.Menezes (11-12 - Hatschbach \& Ferreira 35399.) Fig. 11 - Lobo da corona com antera. Fig. 12 - Estilete com 3 estigmas laterais. 


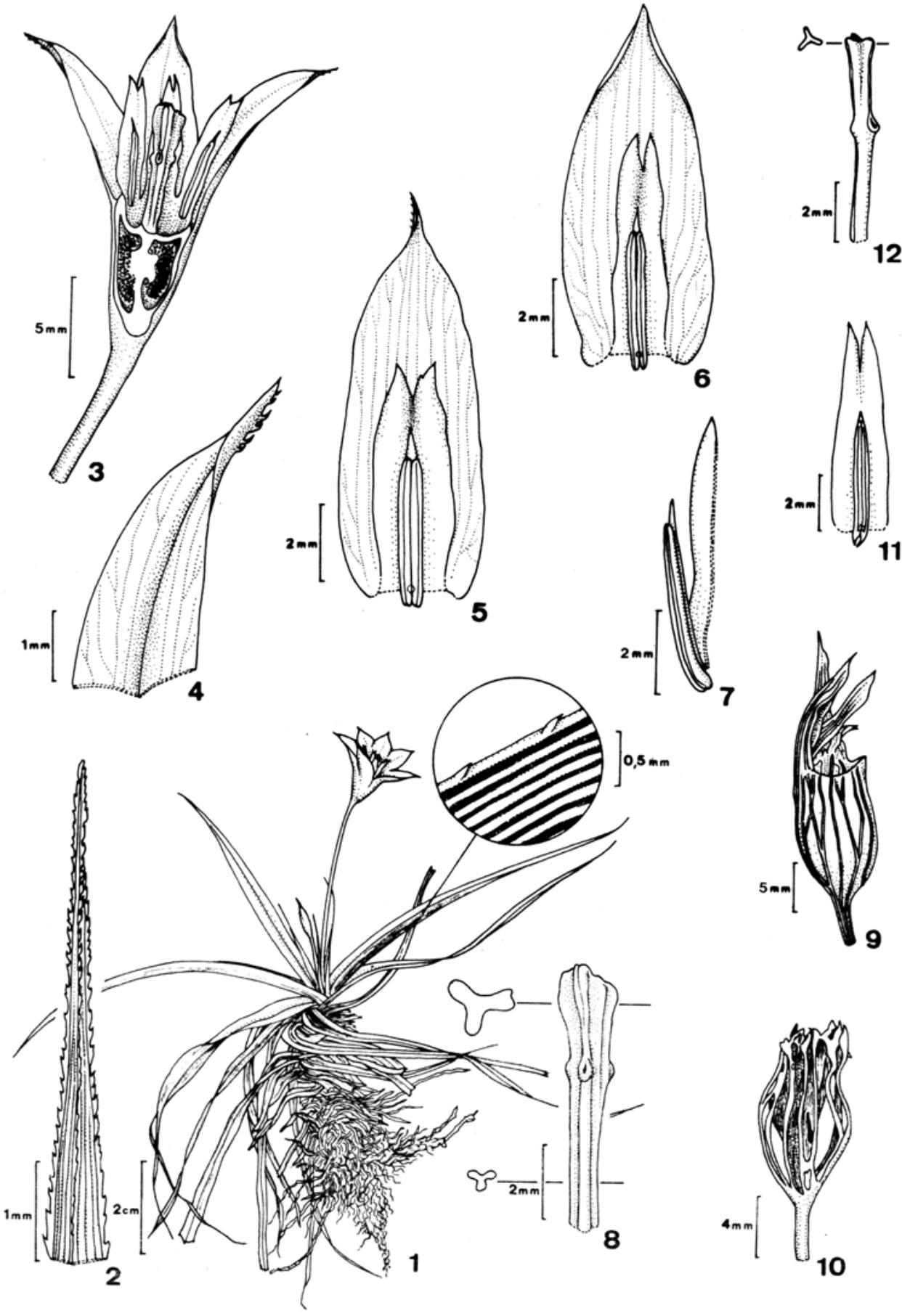


glabro. Flores com hipanto campanulado-trígono, alvo-esverdeado, às vezes com manchas arroxeadas, glabro, 6-7 x 3-5 mm no ápice, o ovário ocupando 3/4 do comprimento; tépalas glabras, oblongas, as externas longamente cuspidadas, alvas a alvo-arroxeadas, 6-13 $\times 2-4 \mathrm{~mm}$, as internas acuminadas, alvas, $5-11 \times 2-5 \mathrm{~mm}$; lobos da corona oblongos, alvos, ca. $6,0 \times 2,3 \mathrm{~mm}$ os opostos às tépalas externas e ca. $6,0 \times 1,5 \mathrm{~mm}$ os opostos às tépalas internas, bf́fidos, os lobos triangulares, anteras roxas, auriculadas na base e apendiculadas no ápice, basifixas, in'rorsas, ca. $4 \mathrm{~mm}$ compr., atingindo $2 / 3$ do tamanho dos $10-$ bos da corona, pólen amare!o; estilete trígono, alvo, ca. $7 \mathrm{~mm}$ compr., iguais ou ultrapassando o ápice dos : sbos da corona; estigmas 3, laterais na base do terço superior do estilete. Cápsula ovóideo-truncada, verde-acastanhada, depois castanha, costada, glabra, deiscente por desintegraçãc do tecido entre as costelas, ca. $10 \times 6 \mathrm{~mm}$. Sementes cônicopiramidais, ca. $1 \mathrm{~mm}$ compr., testa castanha a brúnea, reticulada.

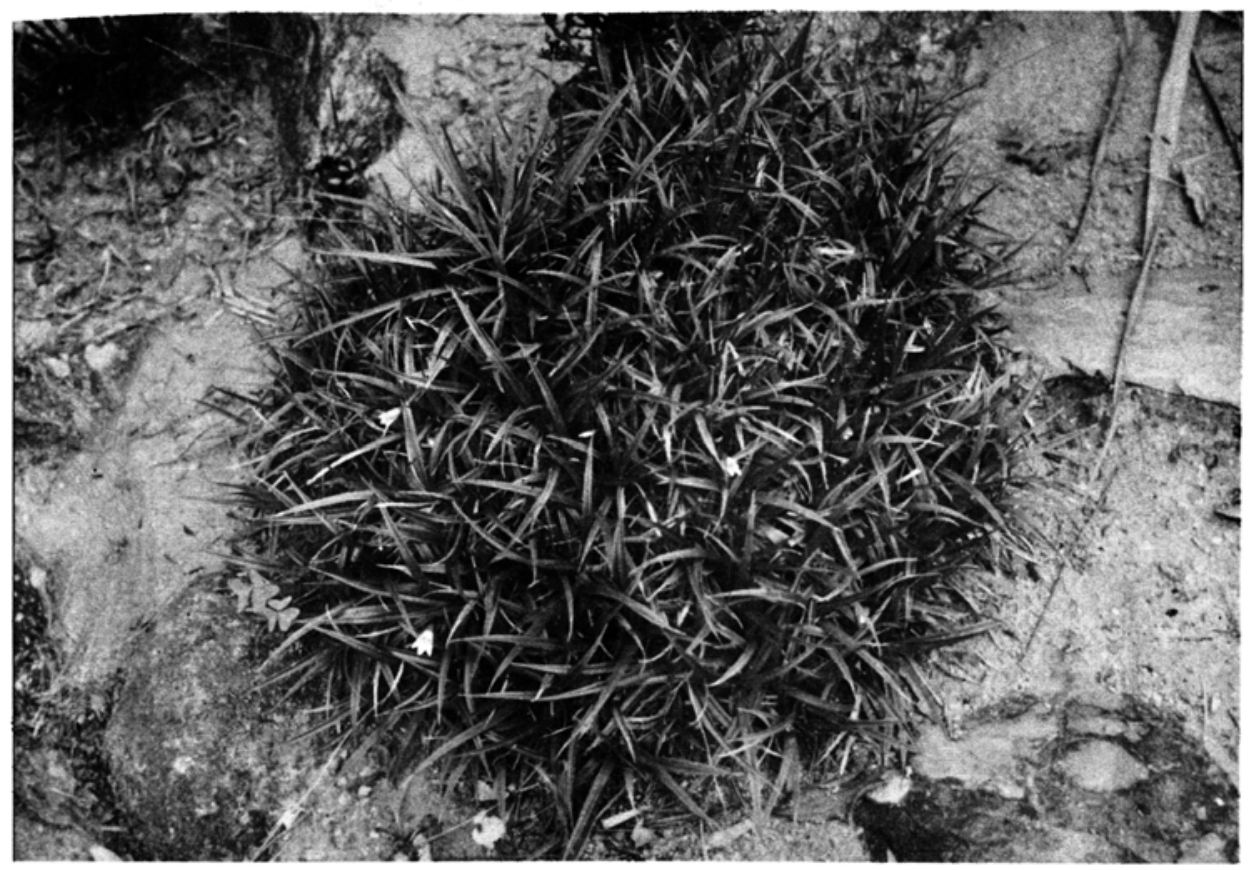

Fig. 13 - Pleurostima riparia (Menezes et al. 1110). Hábito da planta.

Anatomia do limbo foliar na região mediana (Martinelli 5821, Mello-Silva et al. $C F C K$ . 3400, 8874; Menezes et al. 1110; Pirani et al. CFCR 858). Fig. 14

Dorsiventral $€$ n secção transversal. Fendas ausentes. Cutícula espessa em quase əda a superfície adaxial e pouco espessada na superfície abaxial e próximo à nervura :entral na superfície adaxial. Epiderme unisseriada em ambas as superfícies. Estômatos resentes na superfície abaxial e próximos à nervura central na superfície adaxial. Hipojerme unisseriada em ambas as superfícies. Parênquina paliçádico com 3-4 camadas de :élulas na porção superior da lâmina, parênquima aqǘfero com 3-4 camadas de células 
buliformes na porção mediana da lâmina e sobre a nervura central, e parênquima lacunoso na porção inferior da lâmina. Feixes fibro-vasculares envolvidos por bainha dupla, a externa apresentando 2-4 céluias um pouco maiores, laterais aos feixes vasculares; 1 grande vaso presente em cada feixe; 2 cordões floemáticos em forma de $\mathrm{V}$ separados por células de paredes estreitas. Fibras pericíclicas se estendendo até a hipoderme em ambas as superfícies, o conjunto de fibras pericíclicas superior bem mais estreito e um pouco mais longo que o inferior, alguns feixes de fibras envolvidos ou não por bainha subjacentes à hipoderme adaxial. Bordas da lâmina com feixes de fibras de dimensōes medianas. Feixes comissurais presentes.

Typus: Brasil. Minas Gerais. Grão-mogol: "Faz. Jambeiro, vale do rio Itacambiruçu". R.Mello-Silva, T.B.Cavalcanti, D.C.Zappi, J.R.Pirani \& M.L.Kawasaki CFCR 8400, fl. fr., 4.9.1985 (SPF, holotypus; K, RB, SP, US, isotypi)

Paratypi: Brasil. Minas Gerais. Grão-Mogol: “Dos paredões às margens do rio Itacambiruçu", G. Hatschbach 41244, fl., 21.4.1978 (MBM, US); "Faz. Jambeiro, vale do rio Itacambiruçu", G. Martinelli 5821, fr., 9.5.1979 (RB, SPF); "Estrada para Francisco Sá, 5 km de Grão-Mogol, margens do rio Itacambiruçu", N.L.Menezes, I. Cordeiro, A. Furlan, L.Róssi, J.R.Pirani, M.C.E. Amaral \& M.T.Rodrigues 1110, fl. fr., 12.4.1981 (BHCB, F, NY, P, R, SPF); "Beira do rio Itacambiruçu", J.R.Pirani, A. Furlan, I.Cordeiro, M.C.E. Amaral, N.L.Menezes \& L.Rossi CFCR 858, fl., 14.4.1981 (MBM, SPF); "Margens do rio Itacambiruçu, Faz. Jambeiro", R. Mello-Silva, J.R.Pirani, C. Kameyana, I. Cordeiro \& M. Meguro CFCR 8874, fl., 5.1.1986 (SPF).

\section{Obs: CFCR = Coleção Flora de Campos Rupestres}

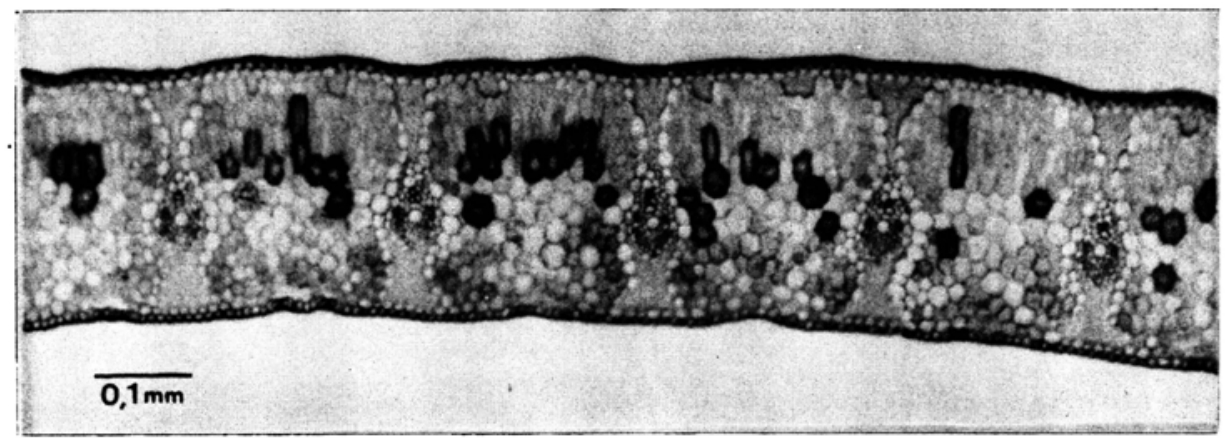

Fig. 14 - Pleurostima riparia, corte transversal da região mediana do limbo foliar (Mello-Silva et al. CFCR 8400).

Pleurostima riparia pertence à secção Pleurostima (Menezes 1980a) com espécies nas montanhas e costa do sudeste brasileiro e na cadeia do Espinhaço, onde geralmente ocorrem nas margens de rios. É muito próxima de $P$. delicatula (L.B. Smith \& Ayensu) Menezes por possuirem.ambas, hipanto glabro, folhas espiro-trísticas, bainhas com ápice exposto, flores alvas a alvo-esverdeadas (até lilases em $P$. delicatula) e anteras menores que os lobos da corona. Além disso, o estilete de $P$. riparia é, no aspecto geral, idêntico ao de $P$. delicatula, com 3 estigmas laterais situados na base da parte apical do estilete (Fig. 12) e não com 3 estigmas confluindo para o ápice como descrito por L.B.Smith \& Ayensu (1976) para a última. Também os lóbulos da corona, nas duas espécies, são agudos (Figs. 5 , 6 e 11) e não arredondados como referido por L.B.Smith \& Ayensu ( l.c.) para P. delicatula. Além do mais, o hábito cespitoso (Fig. 13) de $P$. riparia é muito diferente do hábito de $P$. delicatura cujas plantas crescem isoladamente ou formando touceiras pouco densas. 
A Tabela 1 apresenta os caracteres de distinção entre as duas espécies. Apesar da sobreposição de alguns deles, elas podem ser separadas suficientemente pelo hábito, pelo aspecto do corte anatômico foliar, pela distância das folhas entre si e pela distribuição geográfica restrita de ambas as espécies.

Além das diferenças salientadas na Tabela 1, uma análise da composição da porção parafínica da cera foliar epicuticular revelou diferenças consideráveis entre as duas espécies (Salatino 1986). P. delicatula apresenta como componente máximo da secção paraffnica da cera foliar epicuticular alcano coin 33 átomos de carbono (77\%), além de alcano com 31 átomos de carbono (15\%) e com 35 átomos (8\%) e não apresenta alcanos com 29 e 30 śto-..os de carbono. Em contrapartida, $P$. riparia apresenta como componente máximo alcano com 31 átomos de carbono (50\%), além de alcano com 33 átomos de carbono (33\%), 29 átornos (10\%) e 30 átomos (4\%) e não apresenta alcano com 35 átomos de carbono.

$P$. riparia foi encontrada com flores em janeiro, abril e setembro e com frutos em abril, maio e seteribro. Exemplares cultivados no Depto. de Botânica do Instituto dt Biociências da Universidade São Paulo, florescem e frutificam várias vezes ao longo do ano. Em Grão-Mogol, na estação das chuvas, plantas dessa espécie chegam a permanecer submersas nas águas do rio Itacambiruçu por períodos de até 20 dias. 


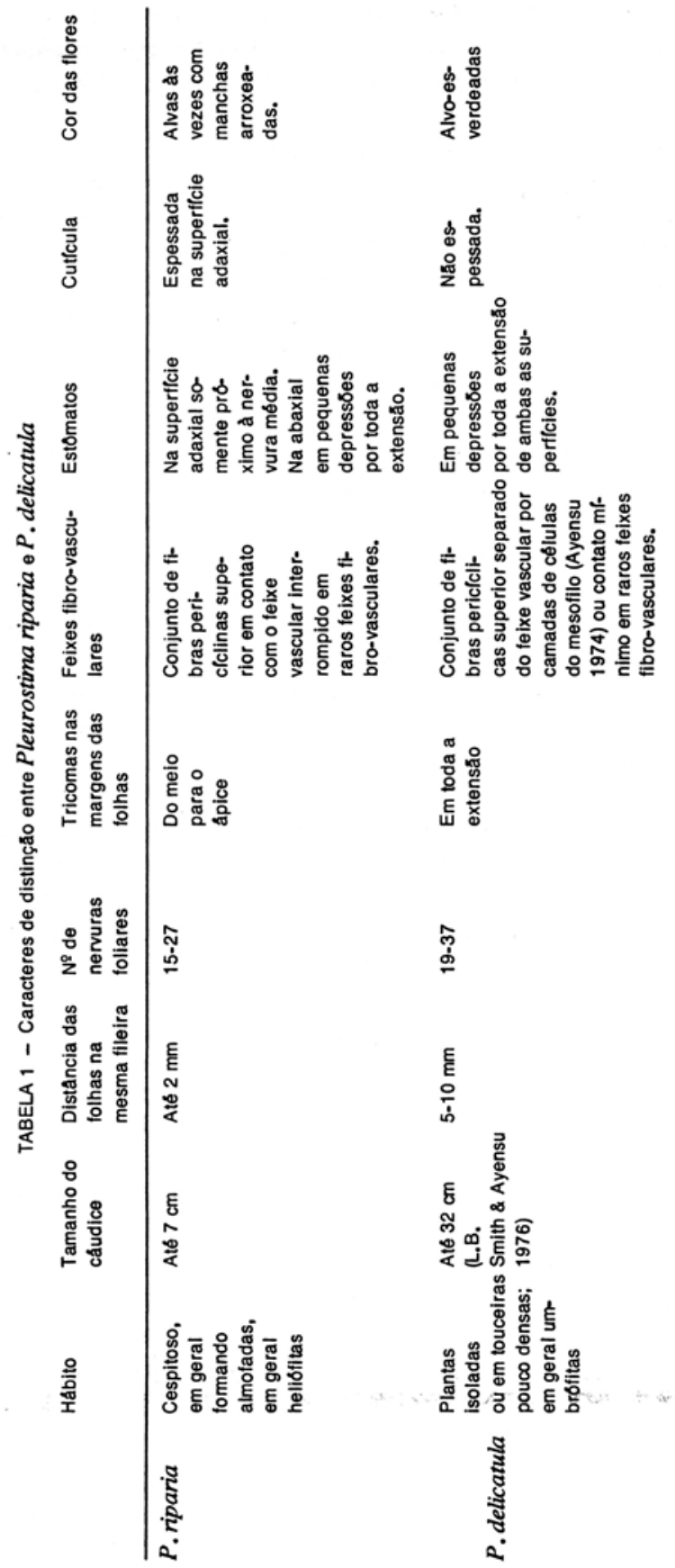




\section{Vellozia luteola Mello-Silva \& N. Menezes sp. nov. Figs. 15-24.}

Ab omnibus speciebus generis floribus luteolis ut videtur sessilibus optime distincta. Species nova floribus luteolis et ovario denso trichomatibus Vellozia sulphurea Pohl similis sed illa folliis linearibus acuminatis supra margineque setosis subtus villosis pedunculo solitario subaequantibus a specie nostra recedit.

Dicta fuit haec planta in allusione colori tepalorum.

Planta caepitosa vel interdum haud caespitosa. Radices rigidae nigricans. Caudex indivisus vel saepius bifurcatus, $2-17 \mathrm{~cm}$ longus, $1-2 \mathrm{~cm}$ latus, apicem versus foliis emarciclis reflexis tectus, basim versus foliorum vaginis $8-20 \mathrm{~mm}$ longis, circ. $15 \mathrm{~mm}$ latis arcte adpressis, plus minusve laceratis resinosis, glabris, fuscis, tectus. Folia trifaria, conferta, chartacea, juniora ereto-patentia, mox patentia, tandem emarcida reflexo-patentia vel reflexa, postrema lacerata, viventia ad 3-13; limbo 4-20 cm longo, ad basem 6-14 mm lato, oblongo, paulo arcuato, carinato, apicem versus supra leviter bicarinato, longo aristato, discolore, supra viridi vel glauco, subtus pallidiore, sicco aut resinoso, interdum non nisi ad base vel limbus foliarum novellorum totus resinosus, marginato, ad medium 32-61 nervis supra inconspicuis, subtus proeminentibus, nervo medio supra impresso subtus prominenti apicem versus strigoso, marginibus incrassatis flavidis, apicem versus vel ad tota extensio tum basim versus sparsim strigosis, cetero glabro. Bracteae anguste triangulares, membranaceae, castaneae, 10-25 mm longae, 3-4 mm latae. Flores subterminales luteoli, ut videtur sessilis; pedunculis circ. 2,s cm longis, $1,5 \mathrm{~cm}$ latis, 1 usque 6 seriatim natis, cylindricis, inferne glabris, superme incrassatis plus minusve trichomatibus parvis cylindricis acutis tectis, in fructificatio elongatis et incrassatis, cir. 3,0-3,7 cm longis, 2,0-2,5 mm latis; ovario obconico-trigono, 3-5 mm longo, 2$3 \mathrm{~mm}$ diam., dense trichomatibus cylindricis acutis, flavo-viridibus, usque $3 \mathrm{~mm}$ longis tecto; tepalis ellipticis, erecto-patulis, apicem versus recurvis, $1,5-2,5 \mathrm{~cm}$ longis, $4-7 \mathrm{~mm}$ latis, 3 exterioribus paulo angustioribus, obtusis cum apiculo, extus basi nervo medioque breviter trichomatibus, cetero glabris, 3 interioribus obtusis, glabris; staminibus 15 in phalanges 6, binis vel ternis, basi filamentorum $2-5 \mathrm{~mm}$ longorum connatis, tepalae adnatis, antheris lateralibusintrorsis, 4-7 mm longis; stylo cylindrico, glabro, 1,0-2,5 cm longo, stigmate trilobo-peltato, luteo, circ. $6 \mathrm{~mm}$ diam. Capsula loculicida, ovoideo-trigona, dense trichomatibus, primo flavovirens tandem straminea, 7-11 mm longa, 4-10 mm diam. Semina conico-pyramidalia, circ. $1 \mathrm{~mm}$ longa, testa badia, reticulato-foveata.

Habitat in fissuris rupibus prope Grão-Mogol, etiam in locis altis petrosis graminosis inter Itacambira et Montes Claros (Minas Gerais).

Planta ern geral cespitosa. Raízes negras, rígidas. Cáudice simples ou bifurcado várias vezes, $2-17 \times 1-2 \mathrm{~cm}$, para o ápice coberto pelas folhas reflexas marcescentes, para a base pelas bainhas foliares. Folhas espiro-trísticas, cartáceas, as jovens ereto-patentes, as adultas patentes, depois marcescentes reflexo-patentes a reflexas e finalmente erodidas, as vivas 3-13; limbo 4-20 cm x 6-14 mm na base, oblongo, longamente aristado, carenado, discolor, na face adaxial verde ou glauco, na abaxial mais pálido, resinoso ou não, às vezes somente na base ou nas folhas muito jovens, marginado, na região mediana 32-61 nervuras inconspícuas na face adaxial e proeminentes na abaxial; nervura média impressa na face adaxial, na abaxial proeminentes e, para o ápice estrigosa; margens amareladas, espèssadas, estrigosas em toda a extensão ou somente para o ápice, restante do limbo glabro. Brácteas estreitamente triangulares, membranáceas, castanhas, 10-25 x 3-4 mm.

Figs. 15-21 - Vellozia luteola Mello-Silva \& N. Menezes (15-20 - Mello-Silva et al. CFCR 10051; 21 - Mello-Silva et al. CFCR 8989). Fig. 15 - Hábito. Fig. 16 - Folha, ápice com arista. Fig. 17 - Ovário com tricomas. Fig. 18 - Corte longitudinal da flor mostrando androceu e gineceu. Fig. 19 - Tépala externa, face adaxial, com estames adnatos na base. Fig. 20 - Tépala interna, idem. Fig. 21 - Frutos, um deles com estilete persistente. 


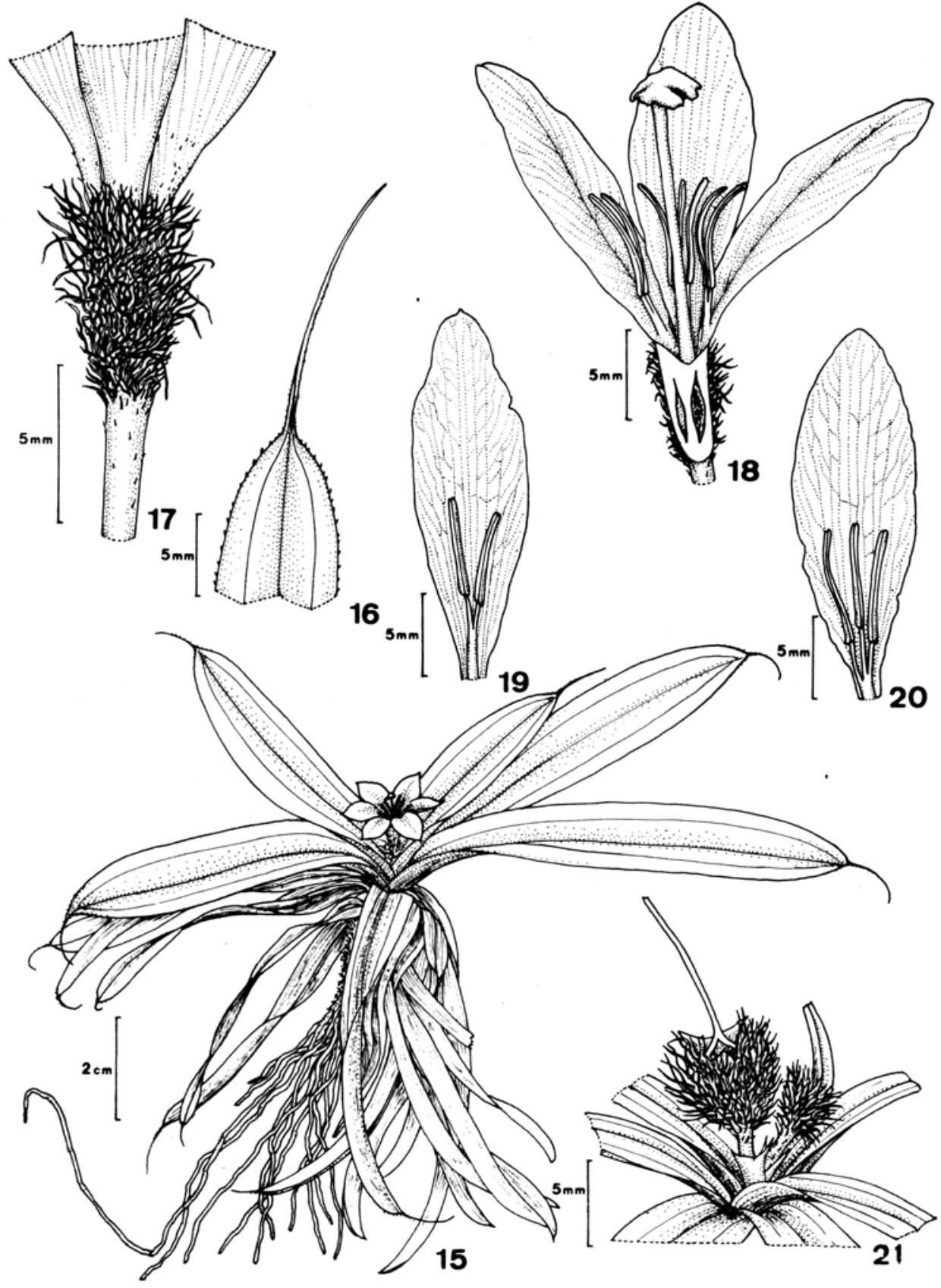


Flores amarelas, aparentemente sésseis; pedúnculos ca. $2,5 \mathrm{~cm} \times 1,5 \mathrm{~mm}, 1$ a 6 surgindo em sequência, cilíndricos, glabros na base, com tricomas subulados no ápice, alongados e espessados na frutificação, até 3,0-3,7 cm x 2,0-2,5 cm; ovário obcônico-trígono, ca. 3-5 x 2-3 $\mathrm{mm}$, densamente coberto de tricomas subulados, verde-amarelados, de até $3 \mathrm{~mm}$ compr.; tépalas elípticas, ereto-patentes, recurvadas para o ápice, 1,5-2,5 cm x 4-7 mm, as 3 externas um pouco mais estreitas obtuso-apiculadas, glabras exceto na base e nervura média da face abaxial, as 3 internas obtusas, glabras; estames 15 em falanges de 2 ou 3 , filetes unidos na base e adnatos às tépalas, anteras 4-7 mm compr., látero-introrsas; estilete 1,0-2,5 cm compr., estigma trilobo-peltado, amarelo, ca. $6 \mathrm{~mm}$ diam. Cápsula loculicida, ovóideo-trígona, densamente coberta de tricomas subulados, amarelo-esverdeada, quando seca, cor-de-palha, 7-11 x 4-10 mm. Sementes cônico-piramidais, ca. $1 \mathrm{~mm}$ compr., testa castanho-escura, reticulado-foveada.

Anatomia do limbo foliar na região mediana (Giulietti et al. CFCR 3555; Hatschbach \& Kasper 41594; Mello-Silva et al. CFCR 8989, 9093, 9701, 10051, 11518). Figs. 22 e 23.
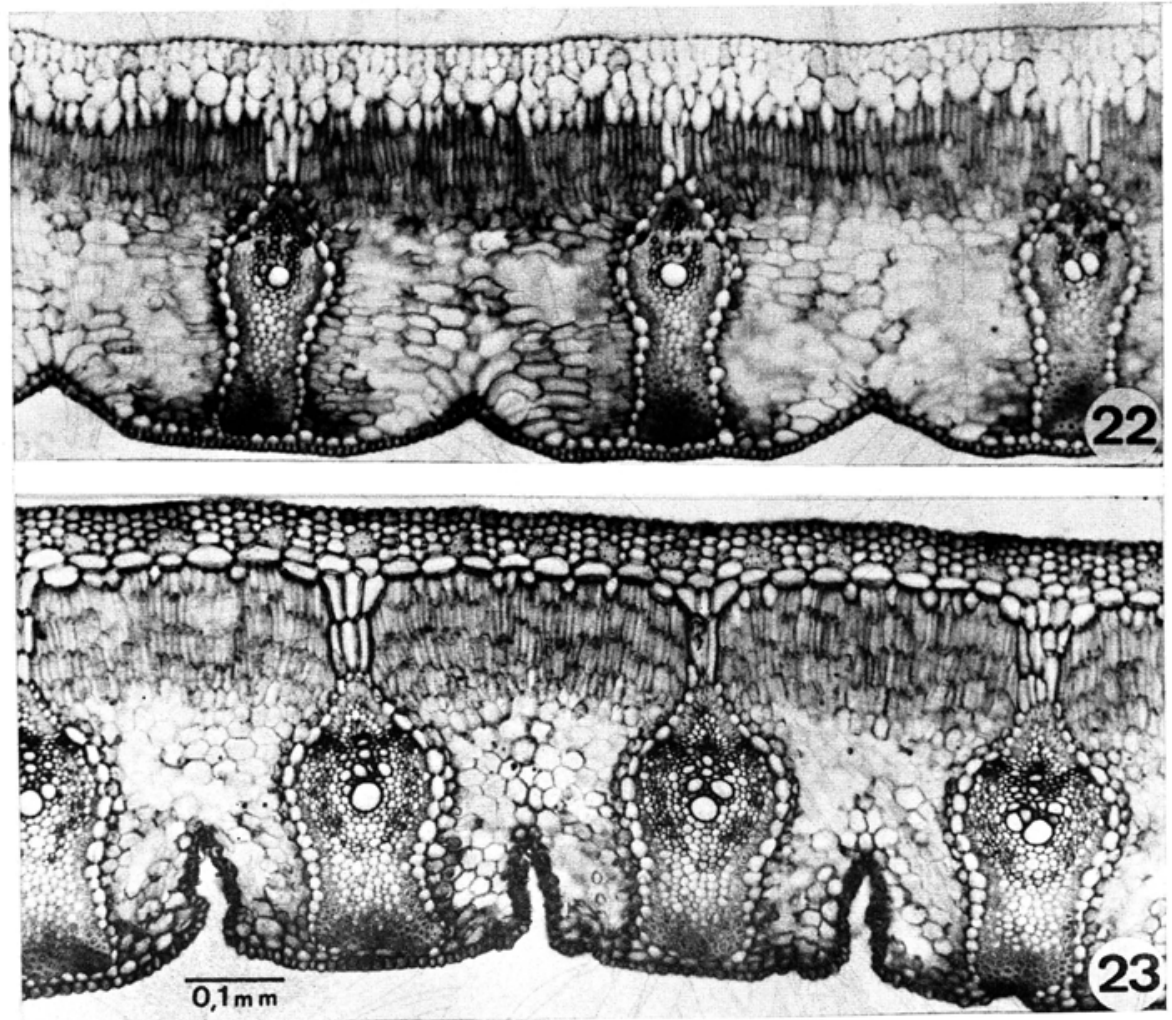

Fig. 22 e 23 - Vellozia luteola (22 - Mello-Silva et al. CFCR 8989, 23 - Mello-Silva et al. CFCR 9093). Fig. 22 - Corte transversal da regiăo mediana do limbo foliar, exemplar de Grăo-M,sogol; Fig. 23 - Corte trasversal na região mediana do limbo, exemplar de itacambira. 
Dorsiventral em secção transversal. Face abaxial com fendas largas e pouco profundas ou fendas ocupando ca. 1/4 da espessura da lâmina e com pequenas projeçōes das células epidérmicas (vide nota). Cutícula pouco espessada em ambas as superfícies. Epidermc adaxial plurisseriada com pequenos feixes de células esclerificadas de espaço em espaço. Epiderme abaxial unisseriada. Hipoderme aquffera 1(-2) seriada, com grandes células na superfície adaxial e unisseriada na abaxial. Estômatos presentes nas fendas ou ía região destas (quando ausentes as fendas). Parênquima aquiffero relacionando a hipoderme com feixes fibro-vasculares somente na metade superior da lâmina, com células buliformes sobre a nervura central e, quando ausentes as fendas, ocupando o lugar destas. Parênquima paliçádico de 3-5 camadas de células e parênquima lacunoso ciistinto . Feixes fibro-vasculares envolvidos por bainha única, com células de aproximadamente 0 nesmo tamanho; 1-3 grandes vasos presentes em cada feixe; 2 cordōes floemáticos late'ais ao xilema e quase paralelos entre si, separados por células de parede espessada. Firas periciclicas se estendendo até o parênquima aquífero na porção superior e até a hipoJerme na inferior; conjunto de fibras pericíclicas superior inconspícuo, em forma de $\mathrm{V}$ invertido, inferior desenvolvido. Bordas da lâmina com feixes fibro-vasculares de grandes dimensões. Feixes comissurais presentes.

Nota: esta espécie apresenta variação no que concerne à presença ou ausência de fendas. Assim é que nos espécimes de Itacambira (MG) as fendas são evidentes conquanto pouco profundas e estreitas. Nos espécimes de Grão-Mogol, as fendas são meras depressōes largas onde se localizam os estômatos e a região do mesofilo sobre estas depressões está ocupada por um parênquima aquffero de células buliformes com o eixo maior disposto horizontalmente.

Typus: Brasil. Minas Gerais. Grão-Mogol: "Vale do riacho Ribeirão. 850 m alt.", R.Mello-Silva \& I.Cordeiro CFCR 10051 FI. fr. 3.9.1986 (SPF, holotypus; K, RB, isotypi).

Paratypi: Brasil, Minas Gerais. Grão-Mogol: “Arredores. Nas infractuosidades de paredões de arenito", G. Hatschbach \& A. Kasper 41594, fl. fr., 18.10.1978 (MBM, SPF, US); "Proximo da ponte sobre o Rio das Mortes. Beira do rio", A.M. Giulietti, M.C.H. Mamede, N. Hensold \& N. Giulietti CFCR 3555, fl., 23.5.1982 (SPF); "Próximo da salda, na estrada para Francisco Sá", R.Mello-Silva, J.R.Pirani, M.Meguro, C.Kameyama \& I.Cordeiro CFCR 8989, fl. fr., 7.1.1986 (L, SP, SPF); "Vale do rio Itacambiruçu. Entre a faz. Jambeiro e estrada para Cristália 700 m s.n.m.," R.Mello-Silva, N.L.Menezes, T.B.Cavalcanti, J.Semir \& N.S. Chukr CFCR 9701, fr., 26.2.1986 (BHCB, NY, SPF, UEC); "Bacia do Ribeirão das Mortes, ca. 950-1000m s.n.m., 42.54'30"W 16!34'S," R. Mello-Silva, J.R.Pirani, I.Cordeiro \& M.C. Assis CFCR 11518, fl. fr., 4.11.1987 (F, SPF); Itacambira: "Estrada para Montes Claros", R.Mello-Silva, I.Cordeiro, J.R.Pirani, M.Meguro \& C. Kameyama CFCR 9093, fr., 9.1.1986 (R,SPF,US).

Obs: CFCR = Coleção Flora de Campos Rupestres.

Vellozia luteola é espécie notável por suas flores amarelas, as folhas longamente aristadas e fortes raizes negras. A cor amarela das tépalas é reportada pela segunda vez para o gênero, antes só referida para $V$. sulphurea Pohl (1827). Com $\in$ xceção destas duas, todas as outras espécies conhecidas de Vellozia (aproximadamente 130), possuem flores roxas com seus diversos matizes ou flores alvas.

$V$. luteola se aproxima ainda de $V$. sulphurea pelo ovário densamente coberto de tricomas nảo glandulares porém, podem ser distintas pelos caracteres apresentados na Tabela 2 . 


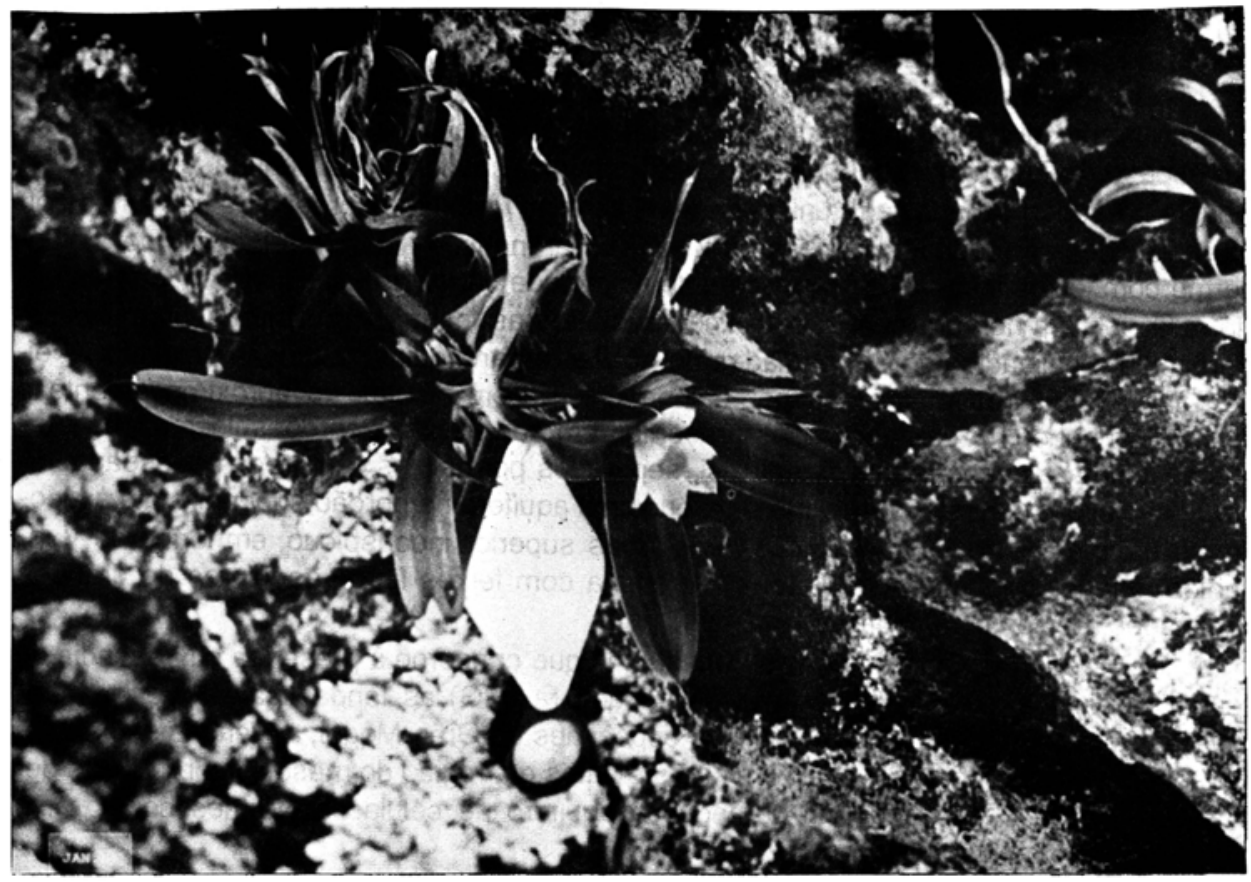

Fig. 24 - Vellozia luteola (Mello-Silva \& Cordeiro CFCR 10051). Hábito da planta.

TABELA 2: Caracteres diferencias entre V. luteola e V. sulphurea

V. luteola
V. sulphurea (Segundo Pohl 1827).
Folhas

Oblongas, longamente aristadas e glabras exceto por tricomas estrigosos nas margens e nervura central

Pedúnculo floral

Flores

estames

Distribuiçăo geográfica
Até 6, muito menores que as folhas, cobertos pelas bainhas foliares, as flores parecendo ser sésseis

Ca. $3 \mathrm{~cm}$. compr.

15 , em falanges de 2 e 3 com filetes menores que as anteras.

Grão-Mogol e Itacambira, norte de Minas Gerais.
Estreitamente triangulares, vilosas.

1, do mesmo tamanho ou pouco maior que as folhas.

Ca. $11 \mathrm{~cm}$. compr.

18, em falanges de 3 , com filetes maiores que as anteras.

Arraial São Joăo Batista (Săo

Tiago,Sul de Minas Gerais); entre Tapanhoacanga e Padre Bento (Alvorada de Minas e Conceiçăo do Mato dentro, centro de Minas Gerais). 
Também relacionada com as espécies acima é $V$. crassicaulis Mart. ex Schultes f., de ampla distribuição (RJ, MG, GO) e que, pelos tricomas do ovário, indumento da folha e tamanho dos filetes se aproxima de $V$. luteola e que, pelo aspecto geral, é bastamte semelhante a $V$. sulphurea. No entanto, diferentemente de ambas, possui flores com tépalas roxas a alvo-arroxeadas.

No aspecto externo, $V$. iuteola assemelha-se muito a algumas espécies de Pleurostima e podem, quando em estado vegetativo, ser facilmente confundidas.

Em Grão-Mogol $V$. luteola ocorre sempre em fissuras de grandes rochas, chegando a formar densas populaçōes agregadas. Em Itacambira, entretanto,colonizam solo arenoso cascalhento entre rochas. Esta espécie foi encontrada com flores em setembro, outubro, janeiro e maio e com frutos em setembro, outubro, janeiro e fevereiro.

\section{Referências Bibliográficas}

AYENSU, E.S. 1974. Leaf Anatomy and Systematics of New World Velloziaceae. Smithsonian Contr. Bot. 15: 1-125.

MENEZES, N.L. de 1971. New taxa and new combinations in Velloziaceae.Cienc. Cult. 23: 421-422.

MENEZES, N.L. de 1973. Natureza dos apêndices petalóides em Barbacenioideac (Velloziaceac). Bolm Zool. e Biol. Mar., (N.S.) 30: 713-755.

MENEZES, N.L. de 1975. Presença de traqueídes de transfusão e bainha mestomática em Barbacenioideae (Velloziaceae). Bolm Botânica, Univ. S. Paulo. 3: 29-60.

MENEZES, N.L. de 1980a. Re-establishment of the genus Pleurostima Raf. (Velloziaceae). Revta brasil. Bot. 3: 37-47.

MENEZES, N.L. de 1980b. Nova espécies e novas combinações no gênero Pleurostima Raf. (Velloziaceae). Bolm Botânica, Univ. S. Paulo 8: 65-69.

MENEZES, N.L. de 1984. Caracteristicas anatómicas e a filogenia na famlia Velloziaceae. Tese de LivreDocência, Univ. S. Paulo.

POHL, J.E. 1827. Plantarum Brasiliae vol. 1. Vindobonae.

SALATINO, M.L.F. 1986. Constituintes da cera foliar epicuticular e a taxonomia de Velloziaceae. Tese de doutoramento, Univ. S. Paulo.

SMITH, L.B. 1985a. Notulae Brasilianae I. Bradea 4(19): 133-134.

SMITH, L.B. 1985b. Notulae Brasilianae I. Bradea 4(23): 157-160.

SMITH, L.B. 1986. Notulae Brasilianae II. Bradea 4(30): 211-214.

SMITH, L.B. \& AYENSU, E.S. 1976. A Revision of American Velloziaceae. Smithsonian Contr. Bot. 30: $1-172$.

SMITH., L.B. \& AYENSU, E.S. 1979. Velloziaceae Brasiliae I. Bradea 2(49): 326-328.

SMITH, L.B.\& AYENSU, E.S. 1980. Velloziaceae Brasiliae II. Bradea 3(14): 105-114. 